\title{
Sistema de valuación salarial para un cabildo municipal en el estado de Guanajuato, en México.
}

Salary valuation system for a municipal council in the state of Guanajuato, in Mexico.

Open Access bajo la licencia CC BY-NC-ND (http://creativecommons.org/licenses/by-nc-nd/4.0/).

Dra. Christian Paulina Mendoza Torres

Dra. Ana Cuevas Romo

Dr. Roberto Hernández Sampieri
Fecha de envío: 4 de Mayo de 2016 Fecha de aceptación: 2 de Julio de 2016 Fecha de Publicación: 31 de Agosto 2016 ISSN: 2007-977X

No. de Reserva: 04-2014-081110025600-203 Vol.1, No.2 2016 


\section{Sumario}

La compensación salarial es una cuestión significativa en la vida de las organizaciones, a su vez, para que ésta sea justa y competitiva se requiere un sistema de tabulación de puestos válido, homologado, confiable y equitativo.

Se procedió a efectuar una investigación holística que identificó las variables que deben incluirse en un sistema de compensaciones salariales abarcando todos los niveles jerárquicos y áreas funcionales. Tal estudio se llevó a cabo en el Ayuntamiento de una ciudad del Estado de Guanajuato, en México. El método utilizado fue el de estudio de caso mixto, con preponderancia cuantitativa; el instrumento de medición y análisis fue el sistema de valuación de puntos, para registrar la información de los perfiles de 224 puestos de las 12 dependencias centralizadas consideradas en la muestra.

El estudio condujo a la propuesta de un método cuyo propósito es orientar a los cabildos a generar un sistema de tabulador de salarios equitativo tomando en cuenta las dimensiones habilidades, responsabilidades, esfuerzo, ambiente laboral y competencia en el mercado.

Palabras clave: Salarios gubernamentales y sistemas de valuación salarial públicos

\section{Abstract}

Salary compensation is a significant matter in every organization, in order to be just and competitive, it is required a system that measures job positions fair and equally.

it proceeded to carry a holistic investigation which could identify the variables need to be included and take in consideration every hierarchic level and functional areas. Such investigation took place in city hall in state Guanajuato, México.

The method used in the investigation was a mixed case study, mostly quantitative .The instrument used for measurement and analysis was a point valuation system, to gather profile information of 224 positions of the twelve branches considered in the sample.

The study led to propose a method, which its main purpose is to orient city councils generating a system capable of valuate equitable wages considering dimensions, abilities, responsibilities, effort, working environment and market competition.
Keywords: Government Salaries, Public Wage Valuation Systems

\section{Introducción}

Las técnicas de las compensaciones salariales son uno de los factores vinculados a la estrategia de desarrollo de las organizaciones, debido a que permiten fomentar la pertenencia, participación e identidad de los colaboradores aspirando al éxito de la empresa y de cada trabajador. El plan, gestión y evaluación de las mismas constituyen un eje en las decisiones productivas, de mercadeo y financieras, ya que, sí éstas se fundamentan en la cultura y filosofía organizacional, harán, se conviertan en una "inversión productiva", como lo señalan Morales y Velandia (2000)

De acuerdo con Robert E. Sibson (como lo cita Robbins, 2010) los tres pasos para lograr una exitosa administración de sueldos es en primera instancia un examen cuidadoso y realista de los objetivos del plan de retribuciones a los colaboradores, en segundo el de desarrollar las políticas de compensación de la empresa que hagan posible la consecución de los mismos; en este sentido en ausencia de tales políticas es probable que la compañía se vea envuelta en constantes crisis referentes a problemas de sueldos, lo cual generará confusiones, desigualdades y problemas. El tercer requisito son los métodos apropiados para la definición de las compensaciones. Dicha técnica, en la cual se ha dado bastante énfasis para elaborar ingeniosos procesos, no debe traducirse en un fin sino en un medio. Lo anterior debido a que deben ser diseñados para ejecutar las políticas de compensación, para auxiliar a resolver problemas de remuneración, y en general, facilitar los logros de objetivos. Al respecto y aludiendo a los fines con los cuales se llevó a cabo el presente estudio, como más adelante se detallará, los métodos para definir los salarios variarán en función de una serie de consideraciones, entre ellas el origen de su capital: privado o público.

Haciendo hincapié en este último, para especialistas en la materia de administración pública, como lo es Klingner (2002) los salarios y sueldos en las oficinas públicas se establecen mediante una variedad de procesos (evaluación de empleos, negociaciones individuales, contratación colectiva, sentencias judiciales), y depende del tipo de sistemas de personal y de la interacción de la ley con la experiencia histórica. 
En la mayoría de los puestos públicos, los salarios se fijan mediante un sondeo que establece la equidad exterior. Esto, se aprovecha como fundamento para proponer y ganar la aprobación legislativa de las estructuras de pago.

En los gobiernos locales o municipales se hace con frecuencia cierto intercambio entre las remuneraciones y los beneficios, por ello resulta difícil determinar el ritmo de aumento en las remuneraciones con respecto a las que se pagan en otras jurisdicciones.

Werther y Davis (2000), reconocen que el proceso de determinar un sueldo gubernamental se ve influido en gran medida por factores como la organización de sindicatos, la productividad de los trabajadores, las políticas de compensación de la empresa y las disposiciones oficiales que enmarcan los sistemas de compensación.

Apuntando al factor de los sindicatos, señalado por Werther y Davis (2000), de acuerdo con el Informe sobre los salarios: Políticas salariales en tiempos de crisis de la OIT de Santiago de Chile (2011), se presentó un análisis salarial de los años 2012-2015 los cuales se caracterizaron por una crisis financiera no suscitada desde la década de 1930, la cual, gracias a los esfuerzos realizados en política mundial contribuyeron a una recuperación en el 2010, aunque la perspectiva continúa siendo incierta. Los datos de cada país muestran que los salarios podrían haber sido más perjudicados en el sector privado que en el público. En este mismo informe se cita a la Unidad de Investigación Internacional de Servicios Públicos (PSIRU-Public Services International Research Unit), la cual argumenta que los ingresos nominales del sector público aumentaron más rápido, o cayeron menos, que los ingresos en el sector privado en 11 de los 18 países europeos. Lo mismo ocurrió en los Estados Unidos, en el plazo de dos años de marzo 2008 a marzo 2010, los trabajadores del sector privado experimentaron un aumento más lento de sus ingresos que los trabajadores estatales y municipales. Los datos preliminares para 2010 indican que esta tendencia se puede invertir en algunos de los países que aplicaron medidas de austeridad para contener la deuda pública y/o que firmaron acuerdos recientes con el FMI. Según el Informe sobre los salarios de la OIT (2011), la naturaleza más robusta de los salarios en el sector público probablemente esté relacionada al mayor nivel de sindicalización de este sector respecto del privado, y además con un mayor grado de coordinación entre los emplea- dos del sector público, además de los modelos para la designación de las compensaciones en organismos gubernamentales.

Al respecto Vargas y Pérez (2006) explican que la técnica acerca de las compensaciones en materia de regulación de los salarios públicos en países como México, es y ha sido un tema de debate, del cual aún no se ha precisado la legitimidad ni el planteamiento a profundidad que debería normar para las organizaciones civiles. Derivado de lo anterior, en México se exterioriza una serie de conflictos emergentes de las brechas salariales entre las remuneraciones promedio de la población y los funcionarios, al ser en estos últimos, superiores a las de otros países más desarrollados. Igualmente los casos en los que un Alcalde se encuentra mejor remunerado que un Jefe de Gobierno de otro país con desarrollo superior o similar al nuestro. De forma paralela, se exhibe la desigualdad si tomamos en cuenta las irregularidades salariales entre cargos del mismo nivel, con diferencias en cuanto a la dependencia, área, entidad federativa o Municipio; o bien, entre poderes públicos.

En este sentido Vargas y Pérez (2006) explican que a diferencia del sector privado, en el cual la fijación salarial se asocia a aspectos de método como la productividad individual y la abundancia o falta de oficios o profesiones, en el entorno público se torna más complejo el análisis y determinación de retribuciones. Dentro de un contexto democrático, las compensaciones públicas se obtienen de los impuestos, por lo que las técnicas han sido un tema reservado a las oficinas gubernamentales de todos los niveles, por tratarse de las remuneraciones de los servidores públicos, los cuales a partir del 2002, con la formación de la Unidad de Acceso a la Información Pública, se autorizó una reforma a las leyes la cual regula la transparencia de los salarios de todos los empleados de la administración pública estatal y municipal. Además de prever que el sueldo para los servidores sea acorde a las funciones y responsabilidades de sus cargos (párr. 9).

De lo anterior se desprende una de las razones por las cuales se argumenta la ejecución del presente estudio, debido a las necesidades del Ayuntamiento estudiado, en el estado de Guanajuato, las cuales oscilaban en función de su tabulador salarial, al requerir establecer nuevas categorías conforme a la valuación de puestos con niveles mínimos, medios y máximos para cada uno de los mismos, a fin de que se pudiera otorgar las pro- 
mociones para los colaboradores de nuevo ingreso a un cargo, comenzando en el nivel mínimo, he aquí la necesidad de la cual se deriva la investigación, buscando que los sueldos para dicho esquema fueran conformes a un análisis de mercado y finalmente ser funcional, equitativo al sector y acorde a las necesidades del municipio. Es así como se originó el planteamiento del problema de la investigación, cuyos objetivos fueron:

- Identificar las variables que deben incluirse para establecer un sistema de tabuladores en la Presidencia Municipal.

- Analizar congruencia, homologación y equidad entre los niveles del tabulador del cabildo.

- Detectar áreas de oportunidad que permitan optimizar el tabulador del Ayuntamiento.

- Evaluar comparativamente los tabuladores de sueldos de la Presidencia Municipal, respecto a puestos equivalentes de otros municipios del Estado y del sector privado de la región.

El cumplimiento de los objetivos nos conduce a un propósito: Proponer un método de cómo los ayuntamientos pueden generar un sistema de tabulador de salarios que sea equitativo con las dimensiones: habilidades, responsabilidades, esfuerzo, ambiente laboral y competencia en el mercado.

Como se aprecia los objetivos se encuentran relacionados entre sí para proponer un sistema de valoración salarial cuya implementación pueda satisfacer las necesidades, anteriormente señaladas, del Ayuntamiento, los cuales buscan responder a las preguntas de investigación: ¿Cuáles son las variables que deben incluirse para establecer un sistema de tabuladores de la Presidencia Municipal? ¿Cuál es la congruencia, homologación y equidad entre niveles de los cargos de dicho tabulador?, ¿Cuáles son las áreas de oportunidad que permiten optimizar el tabulador del Ayuntamiento?, ¿Qué diferencias y semejanzas salariales existirán entre los sueldos de los servidores públicos, respecto a puestos equivalentes de otros municipios del Estado y del sector privado de la región?. Para responder a tales cuestionamientos se utilizó una estrategia de investigación de carácter mixto, con tendencia cuantitativa, a fin de triangular, comparar y complementar con los datos cualitativos, para posteriormente efectuar los análisis pertinentes de acuerdo con la naturaleza de la recolección de información y proponer una valuación salarial, todo lo anterior siguiendo la metodología de valuación de puntos.
Es así como la justificación de la investigación radica en el desarrollo de un sistema, a partir del modelo de puntos, que solvente en primera instancia las necesidades del esquema salarial del $\mathrm{H}$. Ayuntamiento, y en segundo que dicho producto sirva para los fines que así convengan a otros organismos públicos y privados del mismo contexto del estudio de caso de la presente. De tal modo que se comprendan los factores que mide la valuación de los puestos por medio del sistema, otorgar las bases que permitan desarrollar un proceso para la atribución de compensaciones por medio de un modelo de puntos, seleccionar los factores pertinentes de acuerdo con las necesidades específicas de cada entidad privada y/o gubernamental y conocer las formas de diseñar o adaptar un sistema de valuación de puntos para los cargos de una organización, lo anterior considerando la relevancia que el estudio tiene, no sólo para el estudio de caso del cabildo, sino además para otras dependencias de gobierno, cuyos conflictos sean similares a los ya descritos en párrafos anteriores. La investigación pretende contribuir, en la medida de lo posible y en función del acceso a la información, a mejorar la determinación de los salarios públicos, bajo una óptica de criterios cuantitativos y cualitativos, como un medio no como un fin. Ya que se podrían plantear los mismos criterios que rigen en los mercados laborales privados, pero además incluir aquellos criterios intrínsecos al ejercicio público, como la trascendencia política de la toma de decisiones, que aunque son más difíciles de medir, existen metodologías en la materia. Vargas y Pérez (2006, párr. 12) sugieren la importancia de evaluar si el funcionario se apega o no al servicio esperado en función de su perfil y puesto, mediante indicadores de desempeño. Esto deriva en un mejor comportamiento de la organización pública, pues permite identificar y ajustar los casos de funcionarios que se encuentran sobrevaluados o subvaluados, con las respectivas consecuencias.

Aludiendo a Varela (2006) se espera que este estudio sirva como una guía para crear el modelo particular de acuerdo con las necesidades de cada organización, no como un fin, sino como una herramienta para encontrar la orientación de implementar un sistema de compensaciones y administración de sueldos acorde al tiempo y entorno del mercado.

Se parte del principio básico de que cada empresa es diferente a otra, pues tiene su personalidad, cultura y necesidades propias, las cuales no pueden ser transferibles como simples experiencias a otras organizaciones sin las debidas consideraciones y ajustes (Varela, 2006, p.260). 


\section{Metodología}

\section{Enfoque}

El presente proyecto se abordó desde una perspectiva de estudio de caso mixto holístico, con preponderancia cuantitativa, debido al análisis completo y profundo de los puestos que conformaban las direcciones de la administración del $\mathrm{H}$. Ayuntamiento durante el último semestre del año 2014. Además de mantener las características primordiales del paradigma cuantitativo, como lo son la lógica deductiva, delimitación específica del problema de investigación, revisión de la literatura de la cual se adoptaron las características más relevantes de los modelos de valuación de puestos propuestos por otros investigadores y especialistas en el tema, para proceder a la recolección de los datos a raíz del procedimiento fundamentalmente estandarizado y aceptado por una comunidad científica, aunque se adicionaron entrevistas en profundidad.

\section{Alcance y Diseño}

En función de la perspectiva y revisión de la literatura, la investigación tuvo un alcance descriptivo y correlacional. Este estudio utilizó un diseño no experimental transversal descriptivo/correlacional, al pretender realizar un análisis de los elementos que conforman las descripciones de los "puestos clave" de cada área contemplada para el estudio y propuesta de un tabulador salarial durante un momento único en el contexto del ayuntamiento: último semestre del año 2014, periodo durante el cual se llevó a cabo la recolección de datos. Asimismo, el estudio trazó un plan no experimental transversal al indagar la incidencia de las categorías o dimensiones consideradas para gestionar la técnica de valuación de los puestos contemplados por área para el análisis descriptivo de los mismos.

Así pues, la investigación se planeó como no experimental bajo la premisa de que ninguna de las variables fue manipulada de manera deliberada, es decir se observaron las dimensiones y variables correspondientes considerando en cada una como eje las descripciones de puestos, encuestas y entrevistas con los protagonistas o participantes, señaladas en el modelo de puntos: habilidad, esfuerzo (físico y mental), responsabilidad y condiciones de trabajo, más una que se añadió por considerarse preponderante para la investigación: competencia en el mercado laboral y sus respectivas propiedades a evaluar, las cuales se citan más delante en el apartado de instrumento de recolección de datos, de manera concisa.

\section{Población y muestra.}

Considerando que esta investigación tiene un corte de estudio de caso de tipo holístico, la unidad principal de análisis es el $\mathrm{H}$. Ayuntamiento de un municipio de Guanajuato, por lo que a continuación se procederá a delimitar la población dentro del caso, la cual contempló 451 puestos pertenecientes a las direcciones centralizadas, que de acuerdo con el área administrativa (departamento que fungió como contacto al interior del organismo público) era el número total de cargos de los departamentos de la presidencia durante el periodo de recolección de datos. Es importante mencionar que para determinar las unidades de muestreo del estudio, el requisito fundamental de inclusión fue tener la descripción de puestos que fueron otorgados por el área administrativa, a quien en lo sucesivo se le denominará "contacto público". Razón por la que se consideró un muestreo representativo del universo, variado y de diversidad para esta investigación, lo que permitió documentar y localizar patrones y particularidades de cada puesto estudiado, al incluir el análisis de 224 descripciones de distintos niveles jerárquicos y áreas del organigrama.

La muestra se complementó - para fines analíticos y de comparación- con la revisión de las tendencias de compensación del tabulador de salarios de un total de dos empresas privadas y organismos públicos afines a la región geográfica, tamaño y puestos representativos del tabulador objeto del estudio. De manera paralela y en función a lo señalado por la técnica de puntos, se recabo información de 227 colaboradores de la presidencia que ocupaban algunos de los 224 puestos analizados, elegidos mediante un muestreo dirigido de casos-tipo para validar las funciones descritas en sus respectivos puestos.

Debido a circunstancias de acceso a los datos requeridos para la comparación de esquemas salariales y de acuerdo a la naturaleza de la unidad de análisis estudiada, se consideraron cinco organizaciones de la región bajo los siguientes factores de inclusión: (a) organismos de un mismo ramo (cabildos gubernamentales), (b) sistemas con puestos representativos con una extensa variedad de los mismos en diversos niveles. 
En este mismo sentido las características consideradas para la selección de los puestos de que se incluyeron en la comparación fueron: (a) puestos comunes a los investigados, (b) funciones o requisitos similares, sin ser necesariamente iguales, (c) cargos de máxima y mínima remuneración y (d) los salarios no debían transigir de forma severa los efectos de la oferta y la demanda.

Tabla 1. Muestra externa. Análisis de tabuladores en organismos privados y entidades de gobierno

\begin{tabular}{|c|c|c|c|}
\hline \multirow{4}{*}{ 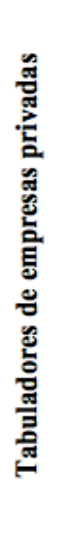 } & $\begin{array}{l}\text { Tabulador de empresa } \\
\text { manufacturera de la } \\
\text { industria automotriz, } \\
\text { maquinaria pesada y } \\
\text { aeroespacial }\end{array}$ & \multirow{4}{*}{ 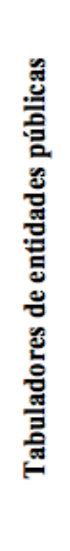 } & Tabulador 1 \\
\hline & \multirow{2}{*}{$\begin{array}{l}\text { Tabulador de empresa de } \\
\text { sistemas de riego }\end{array}$} & & Tabulador 2 \\
\hline & & & Tabulador 3 \\
\hline & $\begin{array}{c}\text { Total tabuladores privados } \\
\mathbf{2}\end{array}$ & & $\begin{array}{l}\text { Total tabuladores de entidades públicas } \\
\mathbf{3}\end{array}$ \\
\hline
\end{tabular}

Tabla 2. Muestra de casos-tipo. Puestos considerados para la aplicación de instrumentos de recolección de datos en el Ayuntamiento

\begin{tabular}{|c|c|c|c|}
\hline Niveles jerárquicos & Nivel directivo & Nivel operativo & Nivel de jefatura \\
\hline $\begin{array}{c}\text { Número de puestos } \\
\text { considerados en la } \\
\text { recoleceión }\end{array}$ & 17 & 115 & 95 \\
\hline Total & \multicolumn{3}{|c|}{$\mathbf{2 2 7}$} \\
\hline
\end{tabular}


Instrumentos de recolección de datos.

La herramienta para realizar el análisis de los 224 puestos fue el instrumento operativo realizado bajo el sistema de valuación por puntos. Dicho instrumento se desarrolló con la finalidad de adaptarse a las descripciones de puesto del tabulador estudiado y la necesidad de sugerir un método que facilitara la asignación de salarios en el cabildo.

De manera paralela y como parte de la técnica de puntos, se utilizó una encuesta y una entrevista semiestructurada, para validar la información de los perfiles de puestos, bajo un método ordenado cuyo propósito general fue recabar datos de los directores de las dependencias centralizadas, operativos y jefaturas acerca de las funciones que normalmente llevaban a cabo como parte de su cargo. De igual manera otro de los objetivos por los cuales se aplicaron los instrumentos fue tener un panorama completo del fenómeno de investigación, validar si las dimensiones y variables del modelo serían las idóneas para los puestos del caso de estudio y de manera posterior sugerir una serie de acciones a implementar para efectuar una justa equidad de salarios en los cargos centralizados.

La encuesta que se aplicó de manera autoadministrada a niveles operativos y jefaturas de las dependencias centralizadas se conformó por un total de 27 preguntas, de las cuales 24 fueron cerradas y tres abiertas para explorar las actividades del puesto.

Las variables medidas fueron: perfil jerárquico del puesto, habilidades, responsabilidades, esfuerzo, ambiente laboral y competencia en el mercado. Dichos instrumentos se aplicaron con previa autorización y apoyo de convocatoria de los departamentos de recursos humanos y "Contacto Público", fueron dichas áreas quienes solicitaron el permiso a las direcciones centralizadas para permitir al personal administrativo y operativo a su cargo acudir a las oficinas de la "Secretaría de Desarrollo Social y Humano" y formar parte del grupo que participaría en el levantamiento de información.

La entrevista semiestructurada se aplicó a 17 directivos con el fin de explorar sus percepciones respecto al perfil de su puesto, habilidades, responsabilidades, esfuerzo, ambiente laboral y competencia en el mercado. Dicho instrumento se conformó por seis preguntas para identificar el nivel jerárquico del puesto y 19 preguntas abiertas de tipo general, estructurales y para ejemplificar sus actividades cotidianas, lo cual permitió contrastar con la descripción del cargo ocupante. Las entrevistas se aplicaron después de concretar una cita, a través del departamento de recursos humanos, de aproximadamente una hora durante su jornada laboral, a las siguientes direcciones:

1.- Ingresos.

2.- Unidad de acceso a la información pública.

3.- Subdirección de Auditorías.

4.- Contraloría.

5.- Proyectos y planeación.

6.- Control municipal.

7.- Asentamientos humanos irregulares.

8.- Fiscalización.

9.- Guardia Municipal.

10.- Subdirección general de la Guardia Municipal.

11.- Desarrollo Urbano.

12.- Tesorería municipal.

13.- Desarrollo Social.

14.- Dirección de Catastro.

15.- Desarrollo Social.

16.- Contraloría.

Como puede apreciarse ambos instrumentos registraron datos sobre las variables y conceptos derivados del sistema de valuación por puntos, con el fin de realizar un análisis efectivo y preciso de las descripciones de puestos para su posterior valoración. Cabe señalar que el análisis de puestos no se relacionó con las personas que actualmente ocupaban los cargos que participaron en el levantamiento de información, ya que en algunas ocasiones el ocupante tenía más habilidades o capacidades que las que la descripción requería o viceversa, por lo que se podría sobrevalorar las funciones para las cuales se requería el puesto en esencia.

\section{Estrategia de Análisis}

Considerando los objetivos de la investigación se procedió a aplicar el modelo de puntos, dentro de los existentes, al considerar que reunía las cualidades necesarias, para llevar a cabo en forma consistente el desarrollo del modelo y cumplir con los fines planteados. A continuación se describe el desarrollo del modelo, con el fin de ilustrar cómo se conjuntaron los datos registrados con los instrumentos de recolección de datos y descripciones de los cargos, para dar pie al análisis de valoración, objeto de este estudio: 
1.- Obtención de información base para la realización del estudio (datos proporcionados por el contacto público). Análisis del tabulador general, conformado por cinco niveles para cada puesto, así como los criterios que habían utilizado para el establecimiento de los esquemas salariales, organigramas de cada una de las doce direcciones centralizadas, así como el organigrama general del Ayuntamiento y la descripción de 224 puestos.

2.- Revisión de tabuladores de otros cabildos y empresas privadas de la región, entre los cuales se encuentran Pénjamo, Apaseo el Alto, Acámbaro, León, una empresa manufacturera de la industria automotriz, maquinaria pesada y aeroespacial, y otra más de sistemas de riego. Así como sus criterios para asignar las compensaciones en cargos equivalentes a los analizados en el Ayuntamiento, objeto de este estudio.

3.- Aplicación de 17 entrevistas a los directores de las dependencias centralizadas, 115 encuestas a puestos de nivel operativo y 95 a nivel de jefatura. Con el fin de validar la información de las descripciones de puesto respecto a las funciones cotidianas del mismo, e implementar en el modelo de análisis las dimensiones y variables según lo recabado. Tal como se detalla en el subproceso de instrumentos de recolección de datos. Al respecto es necesario señalar que en este artículo no se incluyeron los resultados arrojados de las encuestas ni entrevistas debido al proceso de ética con el cual se trataron las respuestas de los participantes; únicamente se consideraron para el análisis global de la información y generación de la tabla de sueldos sugeridos.

4.- Con los datos obtenidos en las fases anteriores se desarrolló un método para generar un sistema de tabulador de salarios equitativo con cinco dimensiones: habilidades, responsabilidades, esfuerzo, ambiente laboral y competencia en el mercado. Dichos factores se implementaron debido a un análisis de las respuestas registradas en las encuestas y entrevistas, las necesidades de la organización y la revisión de literatura en lo que se refiere a la implementación de dicho modelo en otras organizaciones.

Debido a la amplitud de cada actividad efectuada como parte del modelo de puntos, de manera gráfica, la figura uno señala las tareas que se llevaron a cabo para el análisis de la información recabada con el fin de concluir este apartado y dar paso al siguiente donde se describen los resultados obtenidos de los cuales se deriva el "Tabulador de puestos" propuesto al cabildo como producto de los análisis y resultados de este proyecto.

Figura 1. Proceso de análisis para la valoración de puntos por factor

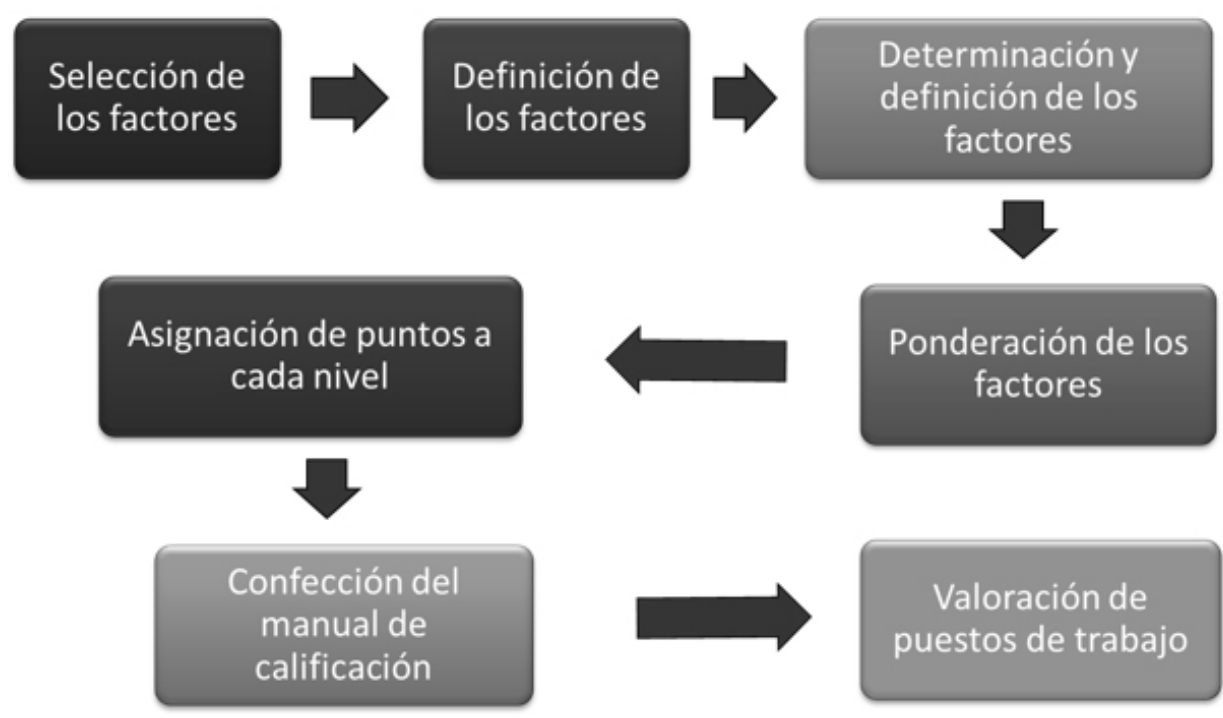




\section{Resultados}

A continuación se ubica la matriz de valuación, producto del análisis de la descripción de puestos, respuestas de las entrevistas y encuestas, y finalmente las tablas donde se aprecian las diferencias y semejanzas entre los tabuladores de puestos en organizaciones públicas respecto al tabulador de salarios del cabildo. El análisis de los resultados se efectuó considerando como principal eje el modelo de valuación por puntos, de tal modo, que la información arrojada por encuestas y entrevistas no se presenta en gráficas, diagramas, o alguna información estadística, ya que de acuerdo con el procedimiento de dicha técnica se procedió a homologar con las dimensiones y variables que conforman la matriz, esta última fungió como instrumento operativo para el análisis descriptivo de los cargos valuados. Para fines de rigor, calidad, honestidad y valor metodológico la valuación de descripciones de puesto se sometió a revisión y aprobación a la Dirección de Personal e Innovación Gubernamental.

A groso modo, uno de las tendencias más sobresalientes, de la aplicación de instrumentos en niveles directivos, jefaturas y operativos fue la percepción que tienen los participantes acerca de la desigualdad en lo que se refiere a la distribución de los puestos y actividades que ejecutan entre cargos de un peldaño jerárquico y otro, ya que pueden ser las mismas funciones, según la descripción del puesto, su percepción, y la brecha entre sueldos se dispara excesivamente en algunos casos, lo cual provoca un ambiente laboral desfavorable y poco motivacional.

Comparativo con tabuladores salariales de organizaciones públicas.

Haciendo alusión a los autores especialistas en administración de compensaciones, como Reyes (2008), Varela (2006) y Morales y Velandia (2000), subrayan la necesidad de determinar la política de salarios y su debida aplicación mediante programas amplios e integrados de administración de sueldos, que se basen en una exacta evaluación de la posición que guarda una organización dentro del mercado de trabajo. Sin embargo, medir el mercado de trabajo representa una tarea compleja de abordar, debido a la confidencialidad de este tipo de información.

A continuación se presenta mediante una tabla comparativa la relación existente entre estructuras de salario de tres ayuntamientos gubernamentales de la región guanajuatense con el tabulador de la Alcaldía, no sin antes aclarar que la información aquí expuesta fue producto de la requisición que se hizo a la Unidad de Acceso a la Información Pública para el caso de las organizaciones gubernamentales y por otro lado del contacto con el área de recursos humanos de los organismos privados, a través del Ayuntamiento.

Las empresas privadas seleccionadas para efectuar la comparación fueron dos: 1.Empresa manufacturera de la industria automotriz, maquinaria pesada y aeroespacial y 2.- Sistemas de riego. Ambas fueron seleccionadas con apoyo de la Alcaldía, por mantenerse dentro de los rangos salariales del municipio, a pesar de que no fueran del mismo giro ni sector, ya que de acuerdo al modelo de puntos bajo el cual se efectuó el estudio, el fin era cotejar con instituciones privadas, cuyos tabuladores mantuvieran una diferencia salarial máxima de $\$ 10,000.00$ en los rangos superiores del organigrama, lo cual ocurría con dichas empresas.

La tabla subsecuente número 3 describe el cotejo realizado entre el tabulador de la Alcaldía objeto de estudio con los esquemas salariales de tres municipios, de tamaño pequeño, mediano y grande, estos últimos fueron seleccionados, como ya se comentó con anterioridad, por ser organismos de índole gubernamental con propiedades en el tabulador requeridas para la debida comparación, por ejemplo los rangos entre los cuales oscilan las remuneraciones: mayor, mediana y menor. Incluso se consideraron los factores de Morales y Velandia (2000) para la identificación de las organizaciones con las cuales se cotejaría el esquema de remuneraciones del cabildo, entre las cuales destacan: ámbito geográfico, tipo de servicio, tamaño de la organización, tipo de puestos, fuentes de reclutamiento, imagen corporativa y origen del capital. Considerando estos factores para ciertos puestos se tomó en cuenta el tabulador salarial de un cuarto municipio del estado, un quinto: propiamente el de Guanajuato, capital y un sexto: Aguascalientes, Aguascalientes.

Los campos, ubicados en los encabezados de las columnas, señalados con una letra " $\mathrm{C}$ " antes del nombre del municipio significan el monto comparativo. Los números positivos reflejan que el sueldo es mayor en el municipio objeto de estudio, que en el municipio con el cual se coteja, por la cantidad mencionada en la columna correspondiente. Los números negativos reflejan que la retribución es menor en la alcaldía principal de la investigación.

Tabla 3. Cotejo con esquemas salariales de gobierno. 
Tabla 3. Cotejo con esquemas salariales de gobierno. $\quad$ DOI: https://doi.org/10.18583/umr.v1i2.20

\begin{tabular}{|c|c|c|c|c|c|c|c|c|c|}
\hline Puestos & $\begin{array}{l}\text { Sucldos } \\
\text { Pénjamo }\end{array}$ & \begin{tabular}{|c|} 
C- \\
Pénjam \\
$0^{*}$
\end{tabular} & $\begin{array}{l}\text { Sueldos } \\
\text { Apaseo }\end{array}$ & $\begin{array}{c}C- \\
\text { Apaseo* }\end{array}$ & \begin{tabular}{l|} 
Sueldos \\
Abasolo
\end{tabular} & $\begin{array}{c}\mathrm{C}- \\
\text { Abasolo } \\
\star\end{array}$ & $\begin{array}{c}\text { Sucldos } \\
\text { León }\end{array}$ & C-León* & $\begin{array}{l}\text { Alcaldia- } \\
\text { sueldos } \\
\text { mensuales }\end{array}$ \\
\hline $\begin{array}{l}\text { Presidente } \\
\text { Municipal }\end{array}$ & $\$ 36,500$ & $\begin{array}{r}\$ \\
51,158.2 \\
1\end{array}$ & $\begin{array}{r}\$ 49,465.7 \\
2\end{array}$ & $38,192.4$ & \begin{tabular}{l|l}
$\$ \$$ & 5 \\
$36,900.0$ & 5 \\
0 & 1 \\
\end{tabular} & $\begin{array}{l}\$ \\
50,758.2 \\
1\end{array}$ & $\begin{array}{r}101,850 \\
15 \\
\end{array}$ & $14,191.948$ & $\begin{array}{l}\$ \\
87,658.21\end{array}$ \\
\hline $\begin{array}{l}\text { Tesor } \\
\text { Muni }\end{array}$ & & $\begin{array}{r}\$ \\
19,812.8 \\
3\end{array}$ & $\$ 19,200.0$ & $29,612.8$ & \begin{tabular}{l|l}
$\$$ & $\$$ \\
$18,990.0$ & 2 \\
0 & 3 \\
\end{tabular} & \begin{tabular}{l|l}
$\$$ & \\
$29,822.8$ & \\
3 & \\
\end{tabular} & 91,293.4 & $42,480.664$ & $\begin{array}{l}\$ \\
48,812\end{array}$ \\
\hline $\begin{array}{l}\text { Director de } \\
\text { Obras Publicas }\end{array}$ & 000 & $\begin{array}{r}\$ \\
8,158.43 \\
\end{array}$ & \begin{tabular}{r|}
$\$ \$ 16,879.3$ \\
5 \\
\end{tabular} & $\begin{array}{r}2 \\
20,279.0 \\
8 \\
\end{array}$ & $\mid \begin{array}{l}3 \\
12,540.0 \\
0\end{array}$ & $\stackrel{5}{2}_{3}^{24,618.4}$ & $\begin{array}{r}78,386.8 \\
8 \\
\end{array}$ & $41,228.45$ & $\begin{array}{l}8 \\
37\end{array}$ \\
\hline Sindico & $\$ 26,000$ & $\begin{array}{r}\$ \\
16,546.0 \\
2\end{array}$ & \begin{tabular}{r|}
$\$ \$ 20,552.2$ \\
3
\end{tabular} & $\begin{array}{r}\$ \\
21,993.7 \\
9\end{array}$ & $\begin{array}{l}\$ \\
26,850.0 \\
0\end{array}$ & $\begin{array}{l}\$ \\
15,696.0 \\
2\end{array}$ & $\begin{array}{r}\$ 46,337 . \\
20\end{array}$ & $-3,791.18$ & $\$$ \\
\hline Regidores & & $\begin{array}{r}\$ \\
13,648.8 \\
4\end{array}$ & \begin{tabular}{r|}
$\$ 20,552.2$ \\
3
\end{tabular} & $\begin{array}{r}\$ \\
17,096.6 \\
1\end{array}$ & $\begin{array}{r}27,900.0 \\
0\end{array}$ & $\begin{array}{l}\mathrm{S} \\
9,748.84\end{array}$ & $\begin{array}{r}\$ 42,998 . \\
80\end{array}$ & $-5,349$ & $\begin{array}{l}\text { s } \\
637,64\end{array}$ \\
\hline $\begin{array}{l}\text { Secretario H. } \\
\text { Ayuntamiento }\end{array}$ & & $\begin{array}{r}\$ \\
25,312.8 \\
3 \\
\end{array}$ & $\begin{array}{r}\$ 20,552.2 \\
3 \\
\end{array}$ & $\begin{array}{r}\$ \\
28,260.6 \\
0\end{array}$ & $\begin{array}{r}13,950.0 \\
0\end{array}$ & $\begin{array}{l}\mathrm{S} \\
34,862.8 \\
3\end{array}$ & $\begin{array}{r}\$ 91,293 . \\
49\end{array}$ & $42,480.66$ & $\begin{array}{l}\$ \\
648,812.83\end{array}$ \\
\hline $\begin{array}{l}\text { Comandante } \\
\text { Seguridad } \\
\text { Publica } \\
\end{array}$ & $7,000.00$ & $\begin{array}{r}\mathrm{s} \\
5,690.71 \\
\end{array}$ & $\begin{array}{r}\$ \\
7,106.57 \\
\end{array}$ & $\begin{array}{r}\mathrm{S} \\
5,584.14 \\
\end{array}$ & $\begin{array}{r}\mathbf{s} \\
7,080,00 \\
\end{array}$ & & $\begin{array}{r}\$ \\
22,186.8 \\
6 \\
\end{array}$ & 9,496 & \\
\hline $\begin{array}{l}\text { Oficial de } \\
\text { Bacheo y } \\
\text { Drenaje } \\
\end{array}$ & $56,000.0$ & $2,752.40$ & & $\begin{array}{r}\$ \\
8,752.40 \\
\end{array}$ & $\begin{array}{r}\$ \\
5,040.00\end{array}$ & $3,712.40$ & \begin{tabular}{|r|}
$\$$ \\
$20,140.0$ \\
0
\end{tabular} & $\begin{array}{r}-\$ \\
11,387.60 \\
\end{array}$ & \\
\hline $\begin{array}{l}\text { Encargado de } \\
\text { Mercados }\end{array}$ & $\$ 7,000.0$ & 1,514.09 & & $8,514.09$ & $5,430.00$ & $\begin{array}{r}\$ \\
3,084,09\end{array}$ & & $\begin{array}{r}\$ \\
8,514.09 \\
\end{array}$ & \\
\hline $\begin{array}{l}\text { Supervisor } \\
\text { Área rural }\end{array}$ & $11,000,0$ & \begin{tabular}{r|}
$-\$$ \\
$3,091.39$ \\
\end{tabular} & & $\begin{array}{r}\mathrm{S} \\
7,908.61 \\
\end{array}$ & $\begin{array}{r}\$ \\
6,810,00 \\
\end{array}$ & $\begin{array}{r}\mathrm{s} \\
1,098.61 \\
\end{array}$ & & $\begin{array}{r}\$ \\
7,908.61\end{array}$ & \\
\hline $\begin{array}{l}\text { Auxiliar } \\
\text { Contable }\end{array}$ & $7,000.00$ & $\begin{array}{r}\$ \\
905.79 \\
\end{array}$ & $\begin{array}{r}\$ \\
9,162.82 \\
\end{array}$ & $\begin{array}{r}-\mathrm{S} \\
1,257.03 \\
\end{array}$ & $\begin{array}{r}\$ \\
4,662.64 \\
\end{array}$ & $\begin{array}{r}\$ \\
3,243.15 \\
\end{array}$ & \begin{tabular}{|r|}
$\$$ \\
$7,918.56$ \\
\end{tabular} & $\begin{array}{r}-\$ \\
12.77 \\
\end{array}$ & \\
\hline $\begin{array}{l}\text { Oficial De } \\
\text { Barandilla }\end{array}$ & $7,000.00$ & 456.77 & $\begin{array}{r}\$ \\
6,007.79\end{array}$ & $\begin{array}{r}\$ \\
1,448.98 \\
\end{array}$ & $5,130.00$ & $\begin{array}{r}\$ \\
2,326.77\end{array}$ & $\begin{array}{r}\$ \\
7,028.86\end{array}$ & 427.91 & \\
\hline
\end{tabular}

1_Por cuestiones de espacio y el número de puestos analizados, únicamente se tomaron un total de 20, procurando representar al organigrama en su totalidad, es decir rangos altos, medios y bajos. 


\begin{tabular}{|c|c|c|c|c|c|c|c|c|c|}
\hline Cajero General & $\begin{array}{r}\$ 7,000.0 \\
0 \\
\end{array}$ & $\begin{array}{r}\$ \\
136.00 \\
\end{array}$ & & $7,136.00$ & & $\begin{array}{r}\$ \\
7,136.00 \\
\end{array}$ & $\begin{array}{r}\$ \\
14,322.8 \\
8 \\
\end{array}$ & $\begin{array}{r}-\$ \\
7,186.88 \\
\end{array}$ & $7,136.00$ \\
\hline $\begin{array}{l}\text { Encargado De } \\
\text { Comunicación }\end{array}$ & $\begin{array}{r}\$ 6,000.0 \\
0\end{array}$ & $\begin{array}{r}\$ \\
857.56\end{array}$ & $\begin{array}{r}\$ \\
10,941.84\end{array}$ & $\begin{array}{r}-\$ \\
4,084.28\end{array}$ & $\begin{array}{r}\$ \\
11,040.0 \\
0\end{array}$ & \begin{tabular}{|r|}
$\$$ \\
$4,182.44$
\end{tabular} & \begin{tabular}{|r|}
$\$$ \\
$19,453.9$ \\
8
\end{tabular} & $\begin{array}{r}-\$ \\
12,596.42\end{array}$ & $\begin{array}{r}\$ \\
6,857.56\end{array}$ \\
\hline $\begin{array}{l}\text { Comandante } \\
\text { De Vialidad Y } \\
\text { Transito } \\
\end{array}$ & $\begin{array}{r}\$ \\
7,000.00\end{array}$ & $\begin{array}{r}-\$ \\
383.57 \\
\end{array}$ & & $\begin{array}{r}\$ \\
6,616.43 \\
\end{array}$ & & $\begin{array}{r}\$ \\
6,616.43 \\
\end{array}$ & & $\begin{array}{r}\$ \\
6,616.43 \\
\end{array}$ & $\begin{array}{r}\$ \\
6,616.43 \\
\end{array}$ \\
\hline Policías & $\begin{array}{r}\$ \\
5,000.00 \\
\end{array}$ & $\begin{array}{r}\$ \\
1,599.50\end{array}$ & & $6,599.50$ & $\begin{array}{r}\$ \\
5,130.00\end{array}$ & $\begin{array}{r}\$ \\
1,469.50 \\
\end{array}$ & $\begin{array}{r}\$ \\
8,586.00 \\
\end{array}$ & $\begin{array}{r}-\$ \\
1,986.50\end{array}$ & $\begin{array}{r}\$ \\
6,599.50 \\
\end{array}$ \\
\hline $\begin{array}{l}\text { Operador } \\
\text { Equipo Pesado }\end{array}$ & $\begin{array}{r}\$ \\
8,000.00\end{array}$ & $1,484.54$ & & $\begin{array}{r}\$ \\
6,515.46 \\
\end{array}$ & & $\begin{array}{r}\$ \$ \\
6,515.46 \\
\end{array}$ & $\begin{array}{r}\$ \\
6,260.80 \\
\end{array}$ & $\begin{array}{r}\$ \$ \\
254.66 \\
\end{array}$ & $\begin{array}{r}\$ \\
6,515.46 \\
\end{array}$ \\
\hline $\begin{array}{l}\text { Auxiliar } \\
\text { Administrativo }\end{array}$ & $5,000.00$ & $\begin{array}{r}\$ \\
1,245.80\end{array}$ & $5,438.10$ & $\begin{array}{r}\$ \\
807.70 \\
\end{array}$ & $\begin{array}{r}\$ \\
5,940.00 \\
\end{array}$ & $\begin{array}{r}\$ \\
305.80 \\
\end{array}$ & $\begin{array}{r}\$ \\
5,957.12 \\
\end{array}$ & $\begin{array}{r}\$ \\
288.68 \\
\end{array}$ & $\begin{array}{r}\$ \\
6,245.80 \\
\end{array}$ \\
\hline $\begin{array}{l}\text { Encargado } \\
\text { Panteón }\end{array}$ & $\begin{array}{r}\$ \\
7,000.00 \\
\end{array}$ & $\begin{array}{r}-\$ \\
2,818.36\end{array}$ & $3,405.40$ & $\begin{array}{r}\$ \$ \\
776.24 \\
\end{array}$ & $\begin{array}{r}\$ \\
4,620.00 \\
\end{array}$ & $\begin{array}{r}-\$ \\
438.36 \\
\end{array}$ & & $\begin{array}{r}\$ \\
4,181.64 \\
\end{array}$ & $\begin{array}{r}\$ \$ \\
4,181.64 \\
\end{array}$ \\
\hline Intendente & $\begin{array}{r}\$ \\
3,500.00 \\
\end{array}$ & $\begin{array}{r}\$ \\
362.12 \\
\end{array}$ & $\begin{array}{r}\$ \\
2,896.92 \\
\end{array}$ & $\begin{array}{r}\$ \$ \\
965.20 \\
\end{array}$ & $\begin{array}{r}\$ \\
3,420.00 \\
\end{array}$ & $\begin{array}{r}\$ \$ \\
442.12 \\
\end{array}$ & \begin{tabular}{|r|}
$\$$ \\
$3,123.12$ \\
\end{tabular} & $\begin{array}{r}\$ \\
739.00 \\
\end{array}$ & $\begin{array}{r}\$ \$ \\
3,862.12 \\
\end{array}$ \\
\hline
\end{tabular}

De acuerdo con las gratificaciones registradas de los municipios señalados en la tabla 4 , así como de la información recabada y analizada de los tabuladores de Aguascalientes y el cuarto municipio de Guanajuato, según Rock (1989) los criterios que se consideran para determinar un sistema salarial competitivo son:

1.- Lo que están pagando otras organizaciones en la comunidad o industria.

2.- Demandas de los sindicatos.

3.- Facilidad para reclutar al personal.

4- Rotación del personal.

5.- Niveles de satisfacción de los empleados.

6.- Competencia del producto o servicio en el mercado.

7.- Utilidades esperadas.

8.- Prestigio de la compañía.

Asimismo, es preciso comentar los criterios señalados por el personal de recursos humanos de las organizaciones privadas consideradas en la muestra del estudio, así como de la información de gabinete recabada en el IACIP (2014): (a) los precios de acuerdo el valor del mercado laboral, (b) la contribución extra del asalariado, (c) la complejidad de la labor que desempeñen, (e) organigrama de la organización, para valorar si el puesto es indispensable de acuerdo a las funciones de otros, (f) personal con la que está integrada el área, (g) preparación académica, (h) experiencia, (i) evaluación por puntos donde se valúa educación, experiencia, nivel de habilidad, esfuerzo físico y mental y responsabilidad, (j) evaluación de alineación en la cual se realiza una comparación de sueldos de los mismos niveles en otras empresas del mismo contexto.

Los criterios para la asignación de salarios en el sector público del estado de Guanajuato, de acuerdo al análisis de gabinete de los esquemas de contribuciones de los municipios elegidos para la investigación, entrevista con el director de recursos humanos del H. Ayuntamiento y revisión de literatura son: (a) carga en el trabajo para las diferentes actividades que se realizan, (b) en apego a los montos máximos y mínimos establecidos por el $\mathrm{H}$. Congreso del Estado, con respecto al artículo 81 de la Ley para el Ejercicio y Control de los Recursos Públicos de los municipios del estado de Guanajuato (2011), (c) el sueldo de los directores de la administración se tasa de acuerdo a las funciones y obligaciones establecidas en los artículos 110, 112, 114 y 117 de la Ley Orgánica Municipal (2011) para el estado de Guanajuato y artículos 82, 83 y 84 de la Ley para el Ejercicio y Control de los Recursos Públicos para los municipios de Guanajuato (2011), (d) grado de responsabilidad del puesto, (e) funciones y obligaciones, (f) rango del nivel en que se ubica el puesto en el que se desempeñará, (g) Situación financiera del municipio en cuestión, considerándose como prioridad. 


\section{Conclusiones}

A continuación se presentan los hallazgos, conclusiones, líneas futuras de investigación y recomendaciones derivadas de los objetivos del estudio empírico efectuado en función del estudio de puestos del H. Ayuntamiento en cuestión. Asimismo se expone el sistema de tabulación salarial, como propuesta de los análisis efectuados mediante el método de puntos a los cargos de 12 dependencias centralizadas, a los cuales se tuvo acceso para la presente investigación. Dicha propuesta fue uno de los objetivos a cumplir de este trabajo.

Derivado de la aplicación y resultados del mismo, se procede a mencionar los siguientes hallazgos:

1.- Ciertos puestos de las dependencias analizadas, ubicados en el organigrama en ramas inferiores, o cuyas funciones y exigencias suelen parecer menores a los de sus superiores inmediatos obtuvieron un mayor puntaje a estos. Lo anterior debido a la distribución de los cargos, la cual resulta desigual en cuanto a niveles se refiere, ya que los ocupantes realizan las mismas actividades y la brecha entre un sueldo y otro se dispara excesivamente en algunos casos, lo cual provoca un ambiente laboral desfavorable y poco motivacional.

2.- Los perfiles de puesto otorgados para el estudio, en algunas ocasiones se encontraban incompletos de acuerdo con los Directores y /o Jefaturas de los departamentos a los cuales se accedió, o bien, en función de lo comentado con el personal que ocupaba los cargos operativos, las actividades señaladas en las descripciones en la práctica cotidiana distaban en gran medida de lo que se hacía, lo cual no se encontraba en los contratos laborales, o algún otro documento de la Dependencia o área de Recursos Humanos.

3.- Para fines de cumplir con uno de los objetivos del estudio: Construir un tabulador equitativo, congruente y homologado, derivado de la detección de áreas de oportunidad del esquema salarial con el cual se trabajó durante la recolección de información, se encontró en términos metodológicos que el número de niveles debía ser suficientes a fin de evitar que, por la agrupación de muchos puestos en un nivel, no existieran diferencias notables entre los sueldos. Estos últimos hallazgos, atienden a uno de los principales conflictos que se percibían en los peldaños medios jerárquicos, entre algunos niveles el aumento sustancial de responsabilidades no era proporcional a las diferencias mínimas salariales de los cargos en niveles inferiores.

Adicionalmente, se considera que los resultados obtenidos en este estudio una vez aplicado el método de puntos, son consistentes con otras investigaciones consultadas para efectuar la investigación, salvo el hecho de haberlo probado para un Ayuntamiento Municipal, por lo cual esta investigación contribuye con una serie de propuestas que se señalan en función de los subprocesos efectuados para cumplir con los objetivos, considerando la naturaleza del organismo con el cual se trabajo, las cuales se mencionan a continuación para ser tomadas en cuenta en futuros estudios de la misma índole:

A. Valuación de los puestos agrupados por niveles jerárquicos, categorías, ocupaciones, cargos similares o unidades, a fin de evitar en la medida de lo posible sobrevaloraciones o infravaloraciones con respecto a cargos que no pertenecen al mismo orden dentro del organigrama organizacional.

B. Selección no solamente de puestos claves, sino además de funciones y actividades importantes, definidas, delimitadas, estables, y cuyos cargos tengan salarios incuestionables, para la comparación con los otros casos que habrán de analizarse.

C. Tal como lo recomiendan Morales y Velandia (2000), y considerando los resultados arrojados en el presente, garantizar la participación de empleados representativos de cada departamento en el diseño de los sistemas de valuación y gestión de planes de remuneración.

D. Considerar en el proceso de valuación, en función del tipo de organización, factores adicionales como: (i) administración de proyectos, (ii) eficacia y eficiencia y (iii) relaciones laborales.

E. A pesar de que los métodos, tanto cuantitativos como cualitativos, consultados en la revisión de literatura para este trabajo consideran el principio de que el puesto es impersonal y debe valuarse sin pensar en el ocupante, se sugiere debido a los cambios en los esquemas organizacionales, incluir el perfil del ocupante y sin duda alguna las necesidades del puesto. 
Se incluye, a continuación la propuesta de esquema salarial efectuada para el Ayuntamiento por niveles, partiendo del tabulador con el cual se designaban las remuneraciones de puestos durante el periodo del 2012 al 2015, dicho tabulador decidió redefinirse, como se comentó en la introducción del estudio, como parte de uno de los objetivos de este estudio, debido a la necesidad de establecer las nuevas categorías conforme a la valuación de puestos con mínimos, medios y máximos para cada uno de los niveles, a fin de que se pueda dar la promoción en alguien que inicia en un nivel mínimo. Además de sugerir sueldos conforme al estudio de mercado laboral, acordes a las necesidades del municipio. Lo anterior en cumplimiento al producto derivado de los objetivos de investigación y en apego a la estrategia de análisis de la información recabada.

Se procede a la inclusión del tabulador sugerido como producto concluyente de la presente investigación, el cual sugiere eliminar dos de los cinco niveles para cada puesto del tabulador original, lo cual significa un total de tres categorías para los once niveles que componen el esquema de compensaciones, con la finalidad de presentar una apertura que oscile entre un mínimo, medio y máximo, de acuerdo a los puntajes de cada categoría. Lo anterior se argumenta en el análisis de la información efectuada con tabuladores de otros ayuntamientos y organizaciones privadas, así como la revisión minuciosa de la literatura acerca de los sistemas salariales para gobierno.

Véase la tabla 4.

Tabla 4. Tabulador sugerido por niveles y puntaje para el H. Ayuntamiento

Tabla 4. Tabulador sugerido por niveles y puntaje para el H. Ayuntamiento

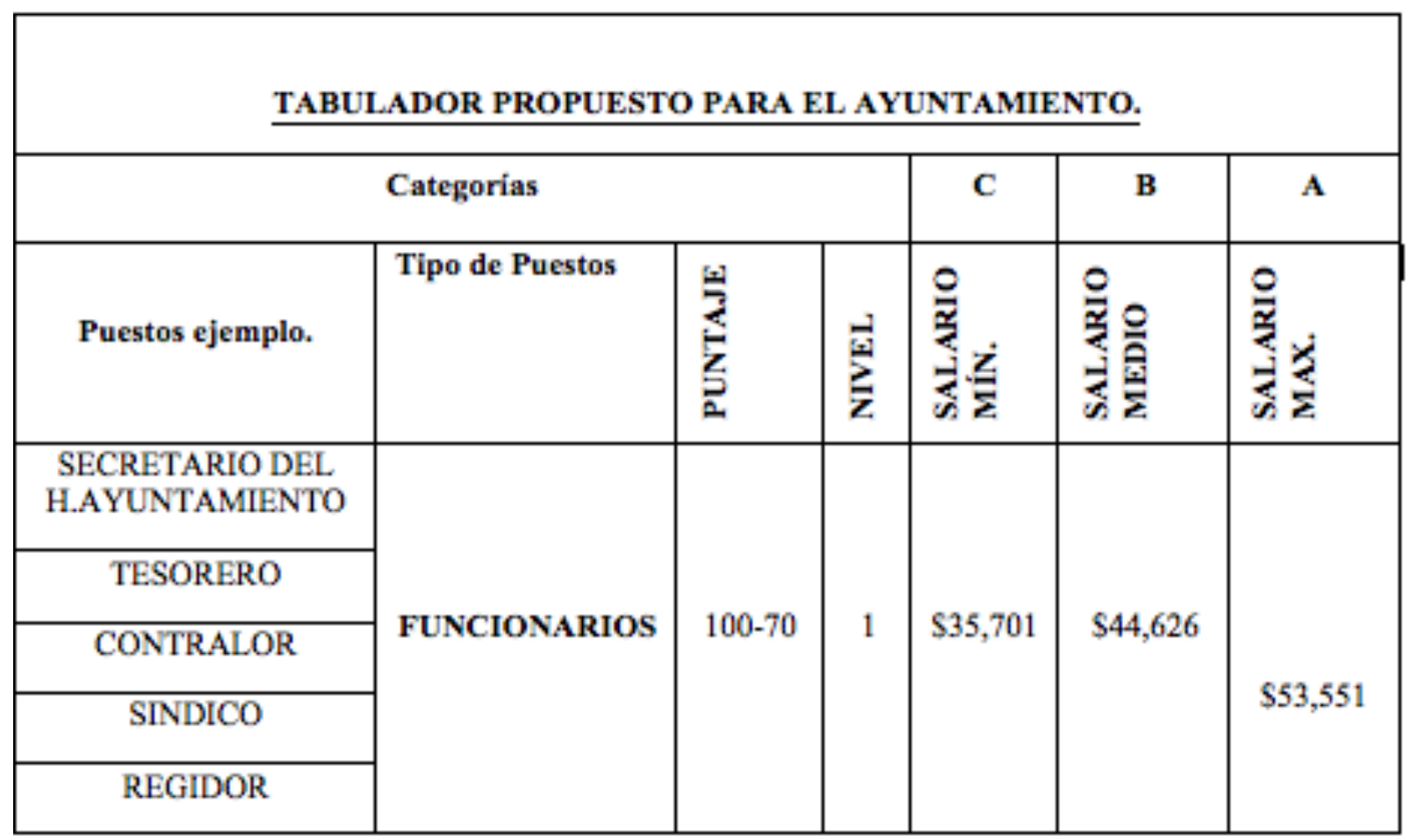




\begin{tabular}{|c|c|c|c|c|c|c|}
\hline DIRECTOR GENERAL. & & \multirow{5}{*}{69.39} & \multirow{5}{*}{2} & \multirow{5}{*}{$\$ 23,679$} & \multirow{5}{*}{$\$ 29,599$} & \multirow{5}{*}{$\$ 35,519$} \\
\hline $\begin{array}{l}\text { SECRETARIO } \\
\text { PARTICULAR DEL } \\
\text { PRESIDENTE }\end{array}$ & & & & & & \\
\hline SUBTESORERO & & & & & & \\
\hline DIRECTOR DE AREA & & & & & & \\
\hline $\begin{array}{l}\text { SECRETARIO DEL } \\
\text { SECRETARIO DEL H. } \\
\text { AYUNTAMIENTO }\end{array}$ & & & & & & \\
\hline $\begin{array}{l}\text { SUBDIRECTOR } \\
\text { GENERAL. }\end{array}$ & & \multirow{4}{*}{38.0} & \multirow{4}{*}{. } & \multirow{4}{*}{$\$ 15,727$} & \multirow{4}{*}{$\$ 19,658$} & \multirow{4}{*}{$\$ 23,590$} \\
\hline $\begin{array}{l}\text { SUBDIRECTOR DE } \\
\text { AREA }\end{array}$ & & & & & & \\
\hline SUPERINTENDENTE & & & & & & \\
\hline ADMINISTRADOR & & & & & & \\
\hline COORDINADOR A & $\begin{array}{l}\text { PERSONAL C / } \\
\text { MANDO. }\end{array}$ & \multirow{2}{*}{$31 \cdot 60$} & \multirow[t]{2}{*}{4} & \multirow{2}{*}{$\$ 12,781$} & \multirow{2}{*}{$\$ 14,202$} & \multirow{2}{*}{$\$ 15,622$} \\
\hline JEFATURA A & & & & & & \\
\hline
\end{tabular}




\begin{tabular}{|c|c|c|c|c|c|c|}
\hline COORDINADOR B & & & & & & \\
\hline JEFATURA B & & 0.30 & 5 & $\$ 9,929$ & $\$ 11,032$ & $\$ 12,135$ \\
\hline JEFATURAC & & & & & & \\
\hline ANALISTA & \multirow{21}{*}{$\begin{array}{l}\text { ADMINISTRA- } \\
\text { TIVO }\end{array}$} & \multirow[t]{5}{*}{$78-50$} & \multirow{5}{*}{6} & \multirow{5}{*}{$\$ 8,078$} & \multirow{5}{*}{$\$ 8,975$} & \multirow{5}{*}{$\$ 9,873.27$} \\
\hline PROKGRAMADOR & & & & & & \\
\hline VETERINARIO & & & & & & \\
\hline JULZCALIFICAIDOR & & & & & & \\
\hline SECRETARIA A & & & & & & \\
\hline MEDICO & & \multirow{5}{*}{$25 \cdot 37$} & \multirow{5}{*}{7} & \multirow{5}{*}{$\$ 6,609$} & \multirow{5}{*}{ \$ 7,344} & \multirow{5}{*}{ \$ 8,078} \\
\hline ENCARGADO A & & & & & & \\
\hline ADXILIAR A & & & & & & \\
\hline ADXILIRR B & & & & & & \\
\hline SUPERVISOR & & & & & & \\
\hline VALDADOR & & \multirow{6}{*}{$12=24$} & \multirow{6}{*}{8} & \multirow{6}{*}{$\$ 4,916$} & \multirow{6}{*}{$\$ 5,462$} & \multirow{6}{*}{$\$ 6,008$} \\
\hline SECRIIARIA B & & & & & & \\
\hline ENCARGADO B & & & & & & \\
\hline PROMOTOR & & & & & & \\
\hline CAJIRO & & & & & & \\
\hline ARCHIVISTA & & & & & & \\
\hline TELEPONISTA & & \multirow{5}{*}{0.11} & \multirow{5}{*}{9} & \multirow{5}{*}{53,263} & \multirow{5}{*}{$\$ 3,626$} & \multirow{5}{*}{$\$ 3,988$} \\
\hline DILEGADO & & & & & & \\
\hline ADXILIARC & & & & & & \\
\hline MAESTRO & & & & & & \\
\hline ENCARGADOC & & & & & & \\
\hline
\end{tabular}




\begin{tabular}{|c|c|c|c|c|c|c|}
\hline BIBLIOTECARIO & & & & & & \\
\hline SECRITARIAC & & & & & & \\
\hline DELEGADO & & & & & & \\
\hline CHOFER & & & & & & \\
\hline HLECTRICISTA & & & & & & \\
\hline SOLDADOR & & $15 \cdot 30$ & 10 & $\$ 2,631$ & $\$ 2,923$ & $\$ 3,216$ \\
\hline VILADOR & & & & & & \\
\hline NOTIFICADOR & & & & & & \\
\hline PELDOQUERO & & & & & & \\
\hline TNTENDENTE & OPERATIVO & & & & & \\
\hline PANTEONERO & & & & & & \\
\hline RECAUDADOR & & & & & & \\
\hline JARDINERO & & 0.14 & 11 & $\$ 2,380.6$ & $\$ 2,645.1$ & $\$ 2,909.6$ \\
\hline ALIBANIL & & & & & & \\
\hline PEON & & & & & & \\
\hline MUSICO & & & & & & \\
\hline SOBDELEGANOO & & & & & & \\
\hline
\end{tabular}

Aludiendo a lo señalado en la estrategia de análisis y para recordar cómo se establecieron los salarios, se señala que con los valores en puntos y salarios que se pagaban en aquel momento por la organización publica, se dibujaron gráficas con valores en puntos, en el eje de las abscisas (x) y en salarios en el eje de las ordenadas (y). Posteriormente se dibujó la línea de tendencia de los salarios, procurando mantener la menor distancia media posible con respecto a los puntos dispersos en la gráfica. De acuerdo con la revisión bibliográfica del modelo de puntos, la línea de tendencia puede calcularse con mayor exactitud mediante la técnica estadística de mínimos cuadrados, este es el método de correlación por excelencia, entre el valor en puntos y el valor en pesos de los cargos considerados. El método de mínimos cuadrados permitió un análisis correlacional lineal simple de dos variables: puntos y salarios. Se tomaron las valoraciones de los cargos en puntos (x) y los salarios que se pagaban a los ocupantes (y), para sugerir un rango salarial en función del proceso descrito. A continuación se muestran tres gráficas que reflejan puestos representativos en los niveles altos, medios y bajos del organigrama objeto de estudio. 
Puesto: Director general

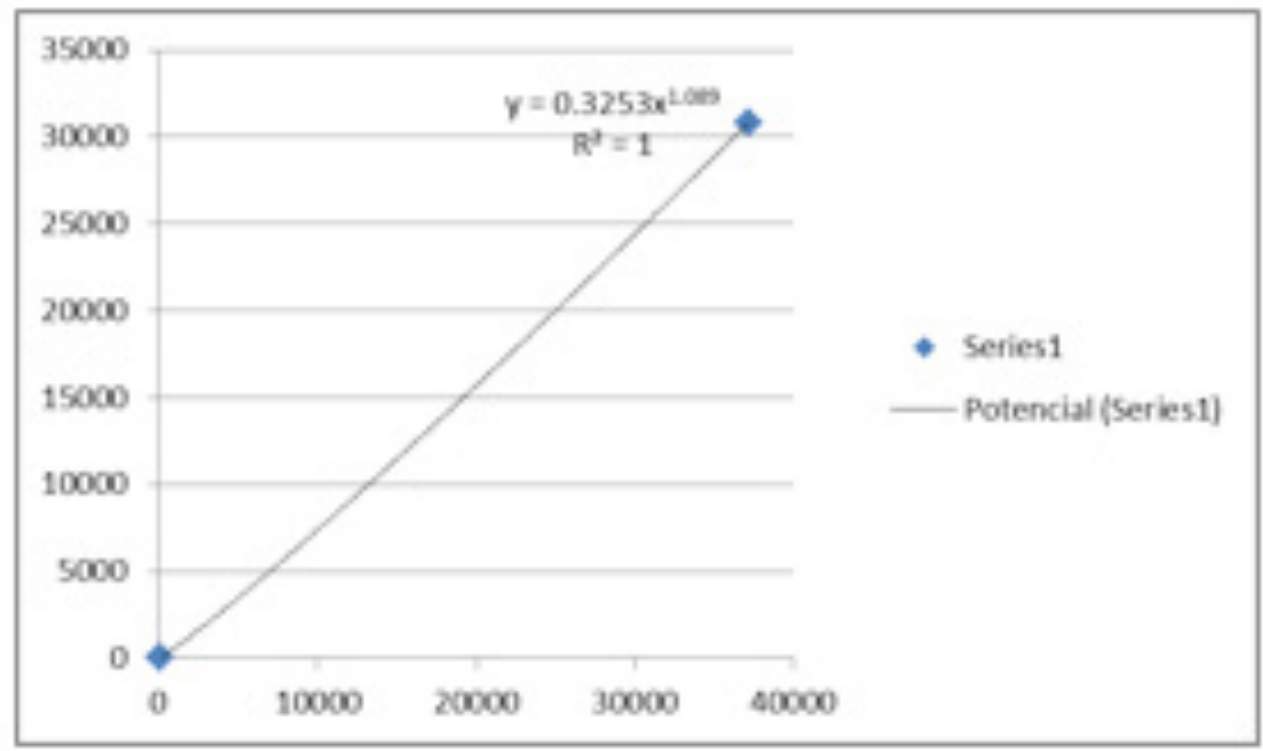

Puesto: Jefatura 1

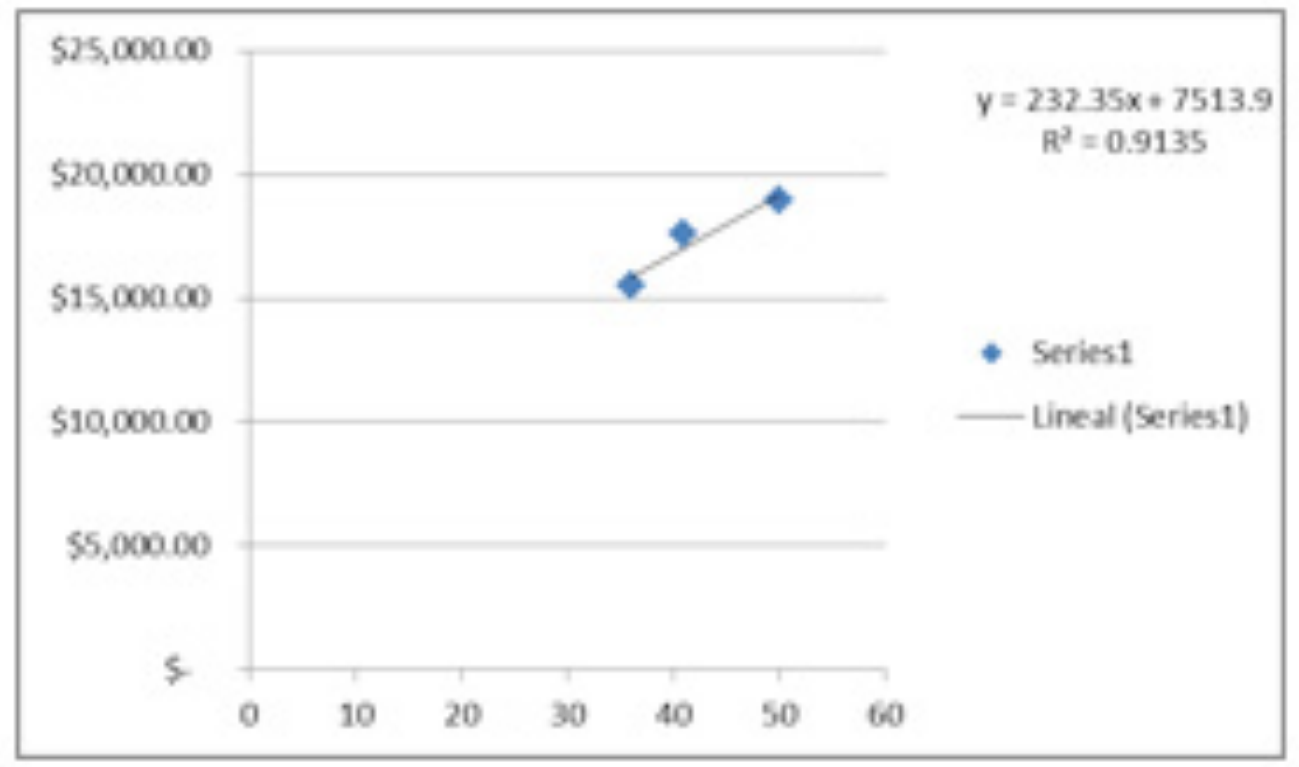

2_Se incluyeron dos jefaturas debido a la variedad de funciones que se identificaron entre los jefes de áreas del Ayuntamiento. 
Puesto: Jefatura 2
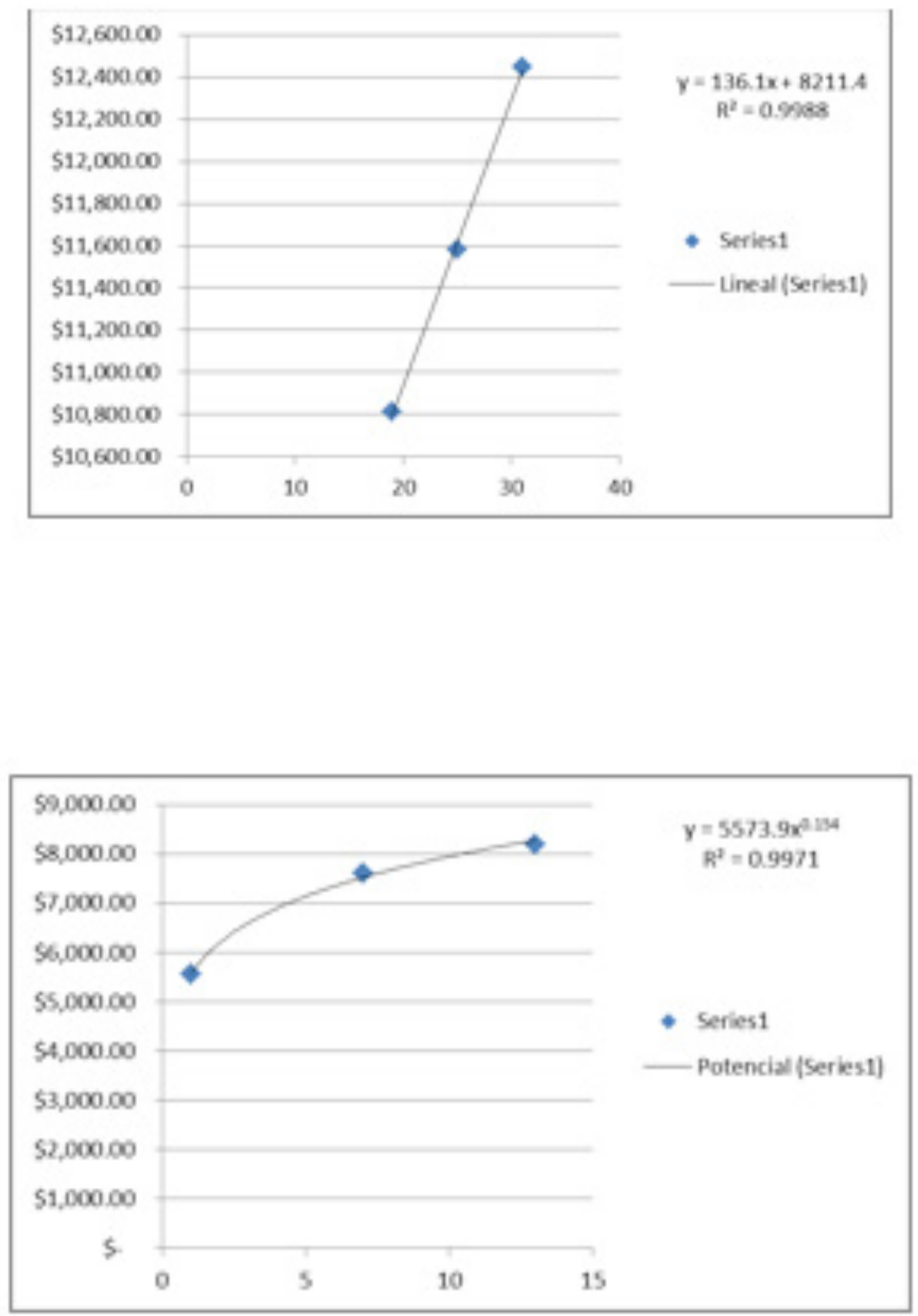
Puesto: Velador
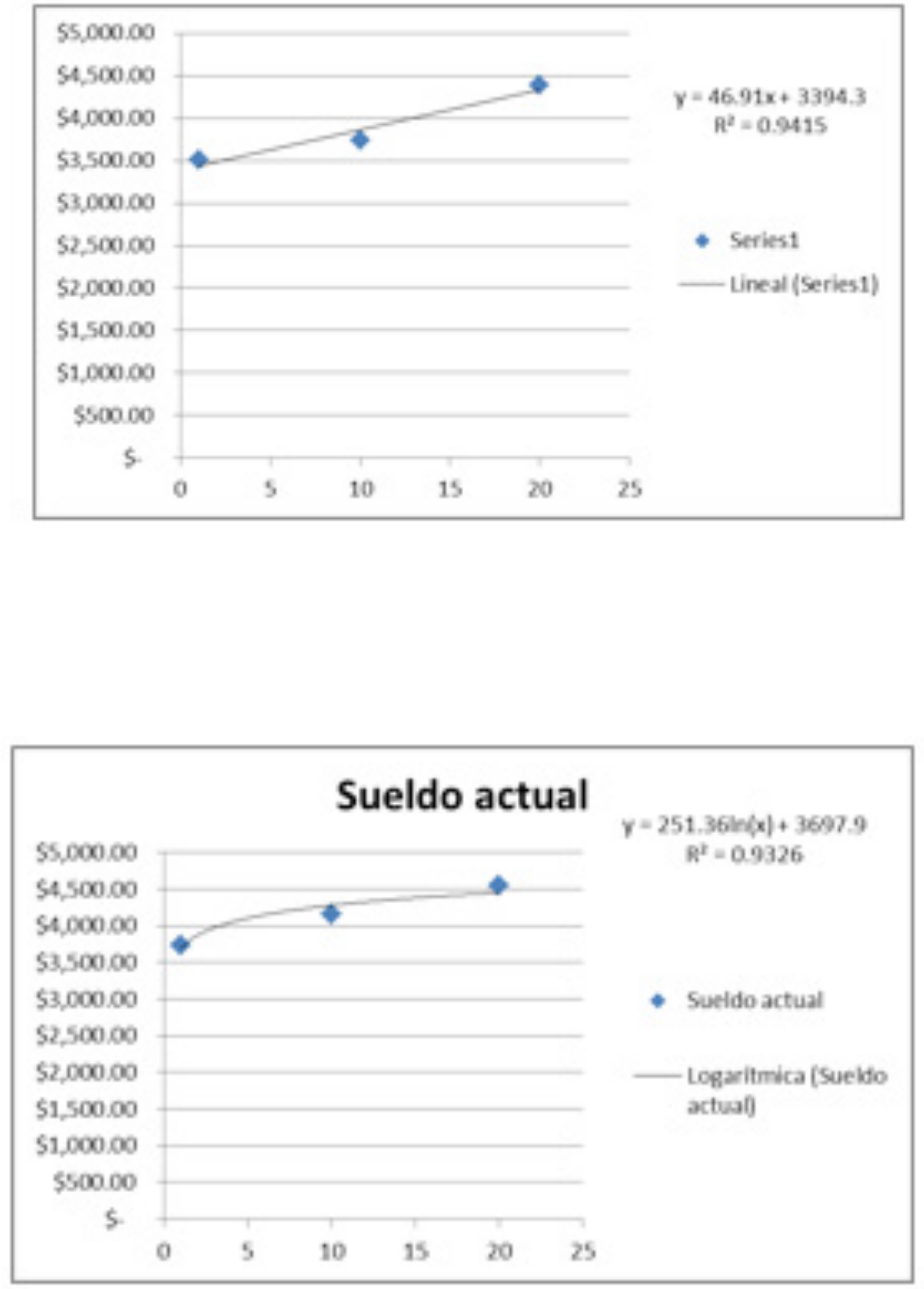
Para finalizar, se proponen las siguientes líneas de investigación derivadas de la investigación:

Aplicar un método para comprobar la eficiencia del modelo. Esto a través de un análisis estadístico de los resultados arrojados por sistema de valuación de puestos propuesto para la organización gubernamental con la cual se trabajo. Uno de los análisis podría ser a partir de una regresión lineal múltiple.

Emplear el sistema de valuación de puestos en otros Ayuntamientos de Gobierno de Guanajuato, incluido el municipio que aquí se estudió y proceder con la gráfica de salarios para la estructura de las retribuciones. Con el fin de probar la irregularidad de las distribuciones que se pagan, perteneciendo incluso al mismo sector, con énfasis en los salarios del personal sindicalizado y el de confianza, así como el cotejo entre departamentos hacia el interior y exterior. Posteriormente, derivado de dicha investigación, se propondrían políticas de compensación apropiadas, buscando la nivelación de las retribuciones, ya sea para elevarlos o para reducirlos.

Probar el sistema de valuación en otros organismos de índole público y privado para efectuar una comparación $\mathrm{y}$ posteriormente identificar las fortalezas y oportunidades del método, así como debilidades y amenazas, según el giro de la organización.

\section{Referencias}

American Psychological Association (2010). Manual de estilo de Publicaciones de la American Psychological Association (3a ed.). México, D.F., México: El Manual Moderno.

Cámara de Diputados del H. Congreso de la Unión (2006). Ley Federal del Trabajo. Recuperado de http:// www.diputados.gob.mx/LeyesBiblio/pdf/125.pdf

Cámara de Diputados del H. Congreso de la Unión (2009). Ley del Seguro Social. Recuperado de http:// www.archivos.ujat.mx/abogado_gral/

legislacion_univ2012/Leyes_federales_02/

LEY_del_Seguro_So-cial.pdf

Congreso del Estado de Guanajuato (2011). Ley Orgánica Municipal para el Estado de Guanajuato. Recuperado de http://www.congresogto.gob.mx/ legislacion/Leyes/acrobat/OMEstado2.pdf

Congreso del Estado de Guanajuato (2011). Ley para el ejercicio y control de recursos públicos. Recuperado de http://www.congresogto.gob.mx/legislacion/ leyes $1 . h t m l$

De Cenzo, D. A. y Robbins, S. P. (2008). Administración de Recursos Humanos. México., D.F., México: Limusa Wiley.

Klingner, D. (2002). La Administración del personal en el sector público (4a. Ed.). México., D.F., México: McGraw-Hill Interamericana.

Morales, J. A. y Velandia N. F. (2000). Salarios: Estrategia y sistema salarial o de compensaciones. Santafé de Bogotá, Colombia: McGraw-Hill Interamericana.

Reyes, A. (2008). Administración de personal: sueldos y salarios. México, D.F., México: Limusa.

Robbins, S. (2010). Cómo fijar salarios. Entrepreneur, 18 (8), 84-87.

Rock, M. L. (1989). Manual de administración de sueldos y salarios. México., D.F., México: McGraw-Hill Interamericana.

Varela, R. A. (2006). Administración de la compensación: sueldos, salarios y prestaciones. México., D.F., México: Pearson Educación.

Vargas, R. y Pérez, H. (2006, octubre). En el Debate. Regulación de salarios públicos. Recuperado de http:// www.derechoasaber.org/editorial_completa.php?id=37

Werther, W. y Keith, D. (2000). Administración del personal y recursos humanos (5a. Ed.). México., D.F., México: McGraw-Hill Interamericana. 
Copyright (c) 2016 Christian Paulina Mendoza Torres, Ana Cuevas Romo y Roberto Hernández Sampieri

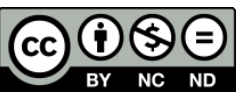

Este texto está protegido por una licencia Creative Commons 4.0

Usted es libre para Compartir (copiar y redistribuir el material en cualquier medio o formato), siempre que cumpla las condiciones de:

Atribución: Usted debe dar crédito a la obra original de manera adecuada, proporcionar un enlace a la licencia, e in dicar si se han realizado cambios. Puede hacerlo en cualquier forma razonable, pero no de forma tal que sugiera que tiene el apoyo del licenciante o lo recibe por el uso que hace de la obra.

No Comercial: Usted no puede hacer uso de la obra con propósitos comerciales

Sin Derivadas: Si remezcla, transforma o crea a partir de la obra, no podrá distribuir la obra modificada

$\underline{\text { Resumen de la licencia }}$ - Texto completo de la licencia 